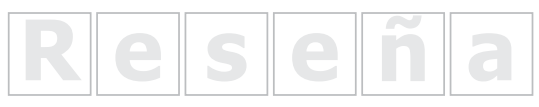





\section{Cooperación para el desarrollo, relaciones internacionales y políticas públicas. Teorías y prácticas del diálogo euro-latinoamericano}

\section{Carlo Tassara, Serie Pensamiento Latinoamericano, Ediciones Unaula, Colombia, 2013.}

doi:10.11144/Javeriana.PAPO19-2.cpdr

\section{Cómo citar esta reseña: \\ Herrera, B. (2014). Reseña del libro Coopera- ción para el desarrollo, relaciones internacio- nales y políticas públicas, por Carlo Tassara. Papel Político, 19(2). 755-757. http://dx.doi. org/10.11144/Javeriana.PAPO19-2.cpdr}

Tres elementos, entre otros, le otorgan a la obra del profesor Carlo Tassara una importancia actual y futura entre las obras académicas publicadas en Colombia y con proyección latinoamericana: 1). una aproximación histórico-teórica a la cooperación internacional, particularmente entre los Estados y las sociedades desarrolladas y sus interlocutores en el denominado (aún hoy) Tercer Mundo; 2) una mirada panorámica, pero profunda sobre las características del funcionamiento de la estructura de la Unión Europea, en tanto que unidad política; y 3) una proyección sobre los derroteros que puede tomar la cooperación internacional y particularmente la denominada sur-sur y las posibilidades de triangulación que ofrece.

La cooperación internacional tradicionalmente fue vista más como un proceso asistencial o paternalista de los gobiernos de los Estados desarrollados y de las organizaciones no gubernamentales o cuasi-gubernamentales que tenían su origen en las sociedades de esos Estados. La cooperación era la herramienta que permitiría crear las plataformas económicas, tecnológicas, políticas, institucionales y sociales que servirían para sacar a las sociedades tercermundistas de su atraso y acercarlas a la modernidad (tal como 
era entendida por las agencias multilaterales mundiales o regionales (para mayor información, recomendamos revisar el Banco Mundial, el Fondo Monetario Internacional o el Banco Interamericano de Desarrollo).

Se podría interpretar esta visión de la cooperación como una extensión de uno de los factores ideológicos que se utilizaron para justificar el colonialismo, es decir, civilizar al salvaje, modernizar al tradicionalista. Esta visión se complementó con la actitud de élites locales que al tiempo que consolidaban su dominio político y económico sobre sus sociedades extendían la mano, en actitud mendicante, a los fondos públicos, semipúblicos y privados ofrecidos por el norte, tanto así que se llegó a definir la cooperación internacional como "el proceso por el cual las élites del norte despojaban a los pobres de sus sociedades para apoyar a los ricos del sur”. Obviamente esta es una caricaturización, pero da una idea del tema que está en el fondo del libro de Carlo Tassara. Él muestra la evolución de las concepciones que han tenido lugar desde el fin de la Segunda Guerra Mundial y particularmente, desde la década de 1950 y cómo se fue avanzando desde esa concepción puramente asistencialista-mendicante a una concepción que valoraba al interlocutor, es decir, a una concepción realmente de cooperación entre las partes sobre la base de problemáticas y de definición de políticas públicas a nivel local, regional sub-estatal, estatal y regional supra-estatal.

El segundo aspecto, al tiempo que aborda la manera como históricamente, a lo largo de sus existencia, la Unión Europea (antes de 1991, las Comunidades Económicas Europeas) ha planteado la temática de la cooperación, sus ámbitos territoriales, y a partir de su propia experiencia, el marco institucional y político que define esa cooperación. En esta parte, el profesor Tassara realiza estudios de caso que muestran la materialización de esta concepción de la cooperación. Aquí, independientemente de los objetivos centrales trazados por el autor, el aporte del autor se concentra en que al realizar la revisión de ese proceso de cooperación Unión Europea-Tercer Mundo y particularmente con América Latina, es posible acercarse de manera clara a la comprensión del funcionamiento de la estructura institucional de la Unión Europea. Para politólogos e internacionalistas -y en general para todos los profesionales de las ciencias sociales- es claro que la Unión Europea no es un Estado, no es un supra-Estado, no es una federación ni una confederación. Sin embargo, manifiesta expresiones de estas cuatro estructuras políticas. ¿Qué es la UE? Es una pregunta que rondará a quienes se dediquen al estudio de las organizaciones políticas de las que se ha dotado la humanidad a lo largo de su historia. El profesor Tassara no se plantea la pregunta y por lo tanto, no busca dar respuesta a la misma pero, al abordar la manera como interaccionan las distintas instituciones que determinan la concepción de cooperación que debe guiar la relación con otros actores y la manera de implementar las políticas acordes con esa concepción y con las capacidades humanas, financieras y logísticas de la UE, nos acerca a la comprensión de ese 
experimento político original y voluntarioso que iniciaron algunos Estados europeos con el fin de construir un sistema que excluyera la guerra de sus relaciones inter-estatales y sirviese de ejemplo al resto de miembros del sistema internacional.

El tercer aspecto a referenciar se relaciona fundamentalmente con la proyección de la cooperación entre Estados y actores internacionales del Tercer Mundo, la llamada cooperación sur-sur. Obviamente este tipo de cooperación es concomitante con el desarrollo de las llamadas 'potencias emergentes' que tienen una experiencia particular al momento de abordar la definición de políticas y procesos que contribuyen a superar (al menos parcialmente) la pobreza, el atraso económico, el deterioro ambiental, etc., y que gracias a su ascenso económico-social y político, disponen de los recursos humanos y la capacidad de proyección hacia otras sociedades. Aquí es importante señalar las posibilidades que este tipo de cooperación ofrece al accionar de las instituciones multilaterales y de los países desarrollados. Podríamos hablar de una triangulación en la definición de políticas y de programas específicos que contribuyan a la construcción de una sociedad global más armónica o al menos más alejada del caos.

En conclusión, entre otros, la obra ofrece estos tres aspectos que son esenciales en la investigación y en los análisis de las problemáticas del sistema internacional que nos ha correspondido vivir. 